\title{
Effect of Three Different Antioxidants on Shear Bond Strength of Composites To Bleached E namel - An In Vitro Study
}

\author{
Murali Mohan $\mathrm{T}^{1}$, Sudha $\mathrm{K}^{2}$, Malini $\mathrm{DL}^{3}$, Bindhu Madhavi $\mathrm{S}^{4}$
}

Quick Response Code

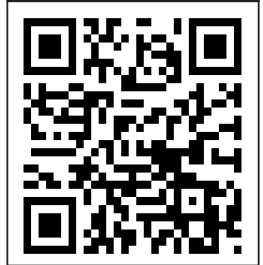

doi: 10.5866/2017.9.10003

1,2,3\&4 Department of Conservative Dentistry \& Endodontics,

Government Dental College and Hospital, Vijayawada.

\section{Article Info:}

Received: J anuary 11, 2017

Review Completed: February 10, 2017

Accepted: March 13, 2017

Available Online: March, 2017 (www.nacd.in) (c) NAD, 2017 - All rights reserved

\section{Email for correspondence:}

muralicons@yahoo.com

\begin{abstract}
:
Context: Bleaching can result in reduced bond strength of composite resin to enamel. To overcome this, bonding procedure should be delayed by a period of 24 hours to three weeks to regain the reduced shear bond strength due to bleaching. To avoid this waiting period various methods have been projected. Among all the methods, the antioxidant treatment has shown immediate improvement in shear bond strength values.
\end{abstract}

Objective: The aim of this in vitro study was to evaluate and compare the effect of $10 \%$ Sodium ascorbate, $10 \%$ Pomegranate peel extract and $10 \%$ Grape seed extract on the bond strength of composite resin to bleached enamel.

Materials and M ethods: Forty flat enamel surfaces were prepared from freshly extracted human premolars using a low speed diamond saw. Then the specimens were divided into four random groups $(n=10)$. All the groups were treated with $30 \% \mathrm{H} 2 \mathrm{O} 2$. The specimens in Group I were bonded immediately after bleaching, whereas Group II, III and IV were treated with antioxidants Sodium ascorbate, Pomegranate peel extract and Grape seed extract respectively. After preparation, a standard shaped resin composite was applied to all specimens. The teeth were stored in deionized water for $24 \mathrm{hrs}$ at $37^{\circ} \mathrm{C}$ and a universal testing machine determined their shear bond strength. The data were evaluated using ANOVA and Tukey Post Hoc tests.

Results: There was a statistically significant difference in the mean shear bond strength among all the groups $(p<0.001) .10 \%$ Grape seed extract showed significantly higher shear bond strength followed by $10 \%$ Pomegranate peel extract and $10 \%$ Sodium ascorbate.

Conclusion: The use of antioxidant immediately after bleaching the enamel surface, completely neutralizes the deleterious effects of bleaching and increases the shear bond strength significantly. Among the antioxidants, $10 \%$ Grape seed extract application after bleaching showed better bond strength.

Key words: Antioxidants, Shear Bond Strength, Composites, Bleached Enamel 


\section{INTRODUCTION:}

Discoloration of the tooth can be a result of both intrinsic $\&$ extrinsic factors. Management of these discolorations can be done conventionally, by using a veneer/crown or more conservatively by bleaching. ${ }^{1-3}$ Various concentrations of peroxide are being used as whitening systems to bleach enamel. Hydrogen peroxide because of its low molecular weight diffuses through enamel, decomposes into oxygen and perhydroxyl free radicals.

Perhydroxyl radicals are not only associated with high permeability and diffusi bility but al so spl it the long chained, dark colored macromolecules of pigments into smaller, less colored and more diffusible molecules which are removed from the structure producing the bleaching effect. Following bleaching, these free radicals react with the organic enamel and can result in morphological alterations, surface irregularities and reduced bond strength of composite resin to enamel.

To overcome this, bonding procedure should be delayed by a period of 24 hours to three weeks to regain the reduced shear bond strength due to bleaching. To avoid this waiting period various methods have been projected for example, utilisation of organic solvent that contain adhesives, alcohol treatment of the bleached enamel surface before restoration, removal of the outermost layer of enamel and the utilisation of antioxidants. ${ }^{4}$ Among all the methods, the antioxidant treatment has shown immediate improvement in shear bond strength values, whereas other methods showed opposing results in regaining the bond strength values.

Hence, the aim of this in-vitro study was to evaluate and compare the effect of three different antioxidants on the shear bond strength of composite resin to bleached enamel.

\section{Materials \& Methods:}

In the present study, 40 recently extracted intact human permanent maxillary premolars were collected and kept in $2.5 \%$ formalin for $48 \mathrm{hrs}$ for disinfection. The teeth were cleaned of any residual tissuetags, pumiced and washed under running tap water.

Specimens were sectioned near the CEJ and then the coronal portion was mounted in a special designed self curing acrylic resin mould in which the longitudinal axis of each specimen was horizontally parallel. The middle third of all teeth were flattened with a diamond disc with low speed hand piece and silicon carbide paper to obtain a standardized smooth enamel surface suitable for the shear bond strength test.

Buccal surface of all the specimens were exposed to $30 \%$ hydrogen peroxide and were randomly divided in to four groups. Three solutions were prepared by dissolving 10gms of Sodium ascorbate, $10 \mathrm{gms}$ of Pomegranate peel extract and 10gms of Grape seed extract in $100 \mathrm{ml}$ of distilled water to make $10 \%$ Sodium ascor bate, 10\% Pomegranate peel extract and $10 \%$ Grape seed extract respectively. Following bleaching, thespecimens were thoroughly rinsed with deionized water for $1 \mathrm{~min}$.

\section{Group I}

(positive control) - Bonding with composite was done immediately following bleaching.

\section{Group II - Bleaching was followed by treatment with $10 \%$ Sodium ascorbate solution for $10 \mathrm{~min}$.}

\section{Group III - Bleaching was followed by treatment with $10 \%$ Pomegranate peel extract solution for 10min. \\ Group IV - Bleaching was followed by treatment with $10 \%$ Grape seed extract solution for 10min.}

This was followed by rinsing with deionized water for 30sec and then bonded with composite. Buccal surface of the teeth were etched with 35\% phosphoric acid for $15 \mathrm{sec}$ (3M ESPE, St Paul, MN, USA), rinsed with water for $15 \mathrm{sec}$ and thoroughly dried to see frosted appearance. A bonding agent (Adper single bond, 3M ESPE, USA) was applied in two consecutive layers with gentle air evaporation between the layers and were light activated for 20 
sec. Then a composite build up (Filtek Z 100, 3M ESPE, USA, shade A3) was placed on the bonded surfaces ( $5 \mathrm{~mm}$ diameter and $2 \mathrm{~mm}$ height) and was light activated for $40 \mathrm{sec}$ with LED light curing unit. All the specimens were stored in deionized water for $24 \mathrm{hrs}$ at $37^{\circ} \mathrm{C}$ prior to shear bond strength testing.

\section{Shear bond strength testing}

Each specimen was placed in between the jigs of the universal testing machine (Model 3345; Instron Corp, Canton, Mass, USA) and a pointed shearing rod was placed on the compositeresin/tooth interface and was subjected to static loading at a rate of $0.5 \mathrm{~mm} / \mathrm{min}$ until fracture occurred.

A one-way ANOVA was used at a confidence interval of $95 \%$. All statistical analyses werecarried out using SPSS software (SPSS Version 13.0). The mean values and standard deviations were used as the descriptivestatistics. Statistical significance was set at $p<0.05$.

\section{RESULTS}

Highest mean shear bond strength value was observed in Group IV, which was statistically significant compared to other groups ( $P<0.001$ ). The mean shear bond strength value of Group II was statistically significant compared to Group IV $(P=0.003)$ but not with that of Group III ( $P>0.05)$. The mean shear bond strength values of Groups III and IV were not statistically significant $(P>0.05)$ (Table 1).

\section{DISCUSSION:}

The reduced bond strength following bleaching was reversed by all the three antioxidants. The compromised bond strength following bleaching is due to the fact that the bleaching agent leaves behind a residual oxygen layer which interferes with the resin infiltration into etched enamel and inhibits the polymerization of resin. 5, 6

Group I showed reduced bond strength, which may be due to the residual oxygen layer that was left behind following the bleaching process. Group III specimens showed comparable values with that of Group II, which supports the fact that the use of antioxidants immediately following bleaching could neutralize the residual oxygen and reverse the reduced bond strength (Table 2). Group IV specimens showed a higher mean shear bond strength value than that of Group I, II and III specimens (Graph 1) which could be attributed to the fact that oligomeric proanthocyanidins present in grape seed extract are powerful antioxidants.

Sodium ascorbate, a derivative of ascorbic acid with a neutral $\mathrm{pH}$ is a potent antioxidant capable of quenching the reactive free radicals. The effect of the residual oxygen layer is neutralized by sodium ascorbate by allowing free radical polymerization of resin base materials to proceed without premature termination by restoring the altered redox potential of the oxidized bonding substrate, thus reversing the compromised bonding. ${ }^{7-9}$

The utilization of plant extracts as a viable alternative to chemical and synthetic antioxidants have been encouraging. In the recent years there is much attention to the nutritional benefits of pomegranate. It has high antioxidant activity due to the high content of phenolic compounds, especially elagic acid. It is claimed that the fruit peel has a higher polyphenol level than the seeds \& pulps. From thetoxological point of view pomegranate peel extract is safe $\&$ non-toxic. ${ }^{10-12}$

Oligomeric proanthocyanidins are a class of polyphenolic bioflavonoids found in fruits and vegetables (grape seed extract, cranberries, pine bark extract, hazel nut tree leaves, lemon tree bark etc). They have free radical scavenging and antioxidant activity with added antibacterial, antiviral, anti-inflammatory, anti-allergic, anticarcinogenic, and vasodilatory actions. ${ }^{9}$ Flavonoids can perform scavenging action on free radicals like superoxide, hydroxyl, and 1,1-dipheny I-2-picrylhydrazyl (DPPH) and have metal chelating properties.

According to the material safety analyses, the level of health hazard for sodium ascorbateis higher than that of oligomeric proanthocyanidins. Furthermore, sodium ascorbate has been found to 
Table 1: Comparison of shear bond strength between the study groups

\begin{tabular}{|l|c|c|c|c|c|}
\hline & \multirow{2}{*}{ N } & \multirow{2}{*}{ Mean } & \multirow{2}{*}{ SD } & \multicolumn{2}{|c|}{ ANOVA } \\
\cline { 4 - 5 } & & & & F-value & p-value \\
\hline Group 1 & 10 & 2.589 & 1.417 & & \\
\hline Group 2 & 10 & 9.038 & 1.237 & \multirow{2}{*}{80.89} & \multirow{2}{*}{$<0.001^{*}$} \\
\hline Group 3 & 10 & 9.899 & 1.429 & & \\
\hline Group 4 & 10 & 11.309 & 1.339 & & \\
\hline
\end{tabular}

$* p<0.05$ statistically significant;

$p>0.05$ Non significant, NS

Table 2: Pair wise comparison of shear bond strength between the study groups

\begin{tabular}{|c|c|c|c|c|c|c|}
\hline \multirow{2}{*}{ (I) Group } & \multirow{2}{*}{ (J) Group } & \multirow{2}{*}{$\begin{array}{l}\text { Mean } \\
\text { Difference } \\
\text { (I-J) }\end{array}$} & \multirow{2}{*}{$\begin{array}{l}\text { Std. } \\
\text { Error }\end{array}$} & \multirow{2}{*}{ p-value } & \multicolumn{2}{|c|}{$\begin{array}{ll}95 \% & \text { Confidence } \\
\text { Interval } & \end{array}$} \\
\hline & & & & & $\begin{array}{l}\text { Lower } \\
\text { Bound }\end{array}$ & $\begin{array}{l}\text { Upper } \\
\text { Bound }\end{array}$ \\
\hline \multirow{3}{*}{ Group 1} & Group 2 & -6.449 & 0.607 & $<0.001^{*}$ & -8.085 & -4.814 \\
\hline & Group 3 & -7.310 & 0.607 & $<0.001^{*}$ & -8.946 & -5.675 \\
\hline & Group 4 & -8.721 & 0.607 & $<0.001^{*}$ & -10.356 & -7.085 \\
\hline \multirow{2}{*}{ Group 2} & Group 3 & -0.861 & 0.607 & $0.50(\mathrm{NS})$ & -2.497 & 0.775 \\
\hline & Group 4 & -2.272 & 0.607 & $0.003 *$ & -3.907 & -0.636 \\
\hline Group 3 & Group 4 & -1.411 & 0.607 & $0.11(\mathrm{NS})$ & -3.046 & 0.225 \\
\hline
\end{tabular}

Tukey Post Hoc test

$* p<0.05$ statistically significant, $\quad p>0.05$ Non significant, NS

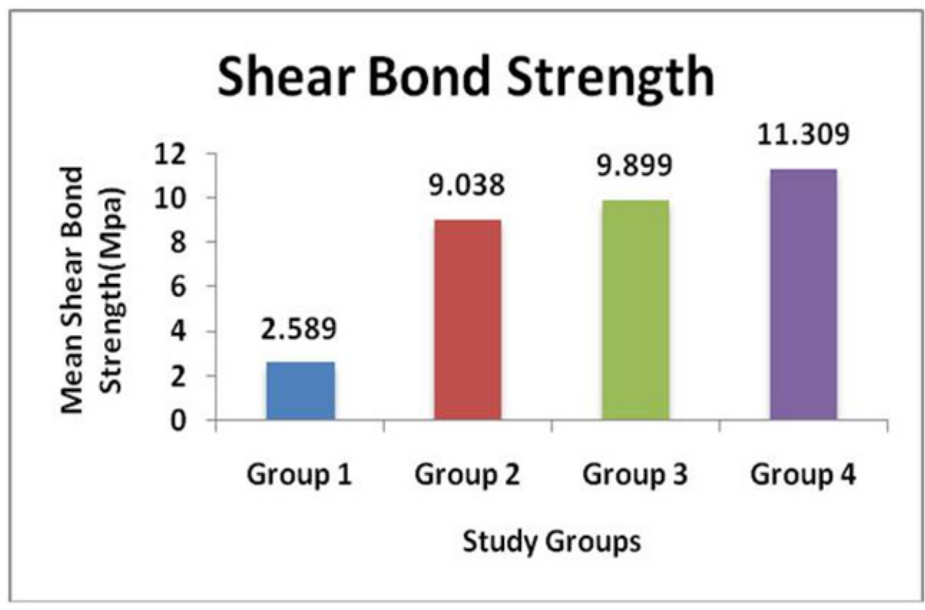

Graph 1: Graphical representation of the comparison of Mean Shear Bond Strength among Groups 
be mutagenic for mammalian somatic cells, while oligomeric proanthocyanidins have no mutagenic effect when their material safety data's were examined. To avoid the waiting period before bonding to bleached enamel natural antioxidants can be used, which makes them clinically significant.

\section{CONCLUSION}

It can be concluded that the treatment of the bleached enamel surface with $10 \%$ Sodium ascorbate, $10 \%$ Pomegranate peel extract and $10 \%$ Grape seed extract reverses the reduced shear bond strength of composite resin.

Among the antioxidants used, $10 \%$ grape seed extract showed increased shear bond strength of composite resin to bleached enamel which was statistically significant.

\section{REFERENCES}

1. Vohra F, Kasah K. Influence of bleaching and antioxidant agent on microtensile bond strength of resin based composite to enamel. Saudi J Oral Dent Res 2014; 5(1):29-33.

2. Kaya A, Türkün $M$, Arici $M$. Reversal of Compromised Bonding in Bleached Enamel Using Antioxidant Gel. Oper Dent 2008; 33(4):441-7.

3. Moosavi H, Maleknejad F, Hoseinipour Z, Hatami L, Zeynali M. Antioxidant Agents and Their Effects on Shear Bond Strength of Bleached Enamel. J Contemp Dent Pract 2013; 14:871-5.

4. Silva J , Botta A, Barcellos D, Pagani C, Torres C. Effect of antioxidant agents on bond strength of composite to bleached enamel with $38 \%$ hydrogen peroxide. Mat Res 2011; 14(2):235-8.
5. Lai S, Tay F, Cheung G, Mak Y, Carvalho R, Wei S et al. Reversal of Compromised Bonding in Bleached Enamel. ýJ Dent Res 2002; 81(7):477-81.

6. Whang $\mathrm{H}$, Shin D. Effects of applying antioxidants on bond strength of bleached bovine dentin. Restor Dent Endod 2015; 40(1):37.

7. Ergun Kunt G, Yýlmaz N, Den S, Dede D. Effect of antioxidant treatment on the shear bond strength of composite resin to bleached enamel. Acta Odontol Scand 2011; 69(5):287-91.

8. Mukka P. An In-vitro Comparative Study of Shear Bond Strength of Composite Resin to Bleached Enamel using three Herbal Antioxidants. J Clin Diagn Res 2016.

9. Mathai V, Christaine Angelo J, Ravi J, Subramonian R. Effect of three different antioxidants on the shear bond strength of composite resin to bleached enamel: An in vitro study. J Conserv Dent 2015; 18(2):144.

10. Miranda T, Moura S, Amorim V, Terada R, Pascotto R. Influence of exposure time to saliva and antioxidant treatment on bond strength to enamel after tooth bleaching: an in situ study. J Appl Oral Sci 2013; 21(6):567-74.

11. Sasaki R, Arcanjo A, Florio F, Basting R. Micromorphology and microhardness of enamel after treatment with homeuse bleaching agents containing $10 \%$ carbamide peroxide and 7.5\% hydrogen peroxide. J Appl Oral Sci 2009; 17(6):6116.

12. Farahnaz sharafeddin, Mehran motamedi, Shiva modiri. Effect of immediate application of pomegranate peel, grape seed and green tea extracts on composite shear bond strength of in-office bleached enamel. Res J Biol Sci 2013; 8(3):83-7.

\section{Gain quick access to our journal online View our journal at www.nacd.in}

